\title{
INFECTIOUS DISEASES, NSW: NOVEMBER 1998
}

\section{TRENDS}

Apart from persistent high numbers of cases of gonorrhoea reported from South Eastern Sydney (mostly related to an outbreak among inner-city gay men - see earlier editions of the Bulletin), case reports of most seasonal notifiable diseases generally were unremarkable (Figure 3 ). In October, there was an increase in reported cases of gastroenteritis in institutions, mainly in the Western Sydney and Central Sydney areas, that was thought to be of viral origin transmitted by person-to-person contact (Table 2). Reports in early November suggest that cases of Ross River virus infection may be starting to increase in some rural areas of the state.

\section{NEW DIRECTOR OF HEALTH PROTECTION}

Mr Ross O'Donoughue has recently been appointed the new Director of Health Protection for NSW Health. Mr O'Donoughue has been acting in this position for much of 1998, and since 1994 has been director of the AIDS/ Infectious Disease Branch. Mr O'Donoughue began his career in public health in health education and community development programs, and so brings to the position a broad public health perspective. The new Health Protection Branch is an amalgamation of the AIDS/ Infectious Diseases, Environmental Health, and Food Branches, and as such mirrors the structures of many public health units, enabling a strong alliance between these components of NSW Health's policy and effector arms.

\section{NSW NEEDLE AND SYRINGE PROGRAM: FEATURES AND PUBLIC HEALTH BENEFITS}

\section{Shaun Davies}

Policy Analyst

AIDS/Infectious Diseases Branch

NSW Health Department

The public health benefits of the NSW Needle and Syringe Program, first implemented in NSW in 1988, are significant. Unsafe drug injecting is a major route of HIV infection; however, the HIV prevalence amongst injecting drug users (IDUs) in Australia has remained one of the lowest in the world, at less than two per cent. This compares favourably with those countries without needle and syringe programs, where HIV prevalence among IDU can be as high as 50 per cent. In many countries, unsafe drug injecting behaviour such as needle sharing now accounts for more HIV infections that unprotected sex. In Malaysia, Vietnam, south-west China, north-east India and Myanmar, 75 per cent of HIV cases are among IDUs. The World Health Organisation estimated that in 1997 injecting drug use was responsible for approximately 43 per cent of the total AIDS cases in the European region. ${ }^{1}$
Features of the NSW Needle and Syringe Program The NSW Needle and Syringe Program has two components - the public sector program and the private sector program - together offering a total of 839 outlets.

The public sector program comprises the following:

- Primary outlets, which in some instances operate as stand-alone, publicly accessible facilities, are often housed and administered through hospital departments such as drug and alcohol units. All other needle and syringe facilities in an area health service are supported by the primary needle and syringe outlet.

- Secondary outlets are serviced by primary outlets and generally are facilities which also provide a range of other health services to the community, such as community and sexual health centres and hospital emergency departments.

- Vending machines are serviced by primary needle and syringe outlets. They provide access to sterile injecting equipment after hours and in areas where it is difficult to provide service. All vending machines are located with disposal bins, which are well utilised.

There are 319 public outlets, including 33 vending machines.

The private sector program operates through the NSW Branch of the Pharmacy Guild of Australia, with approximately 520 members participating in the Pharmacy Fitpack Scheme. Under this arrangement, injecting drug users can purchase or exchange sterile syringes. The costs associated with the exchange of equipment is met by NSW Health.

In 1997-98, approximately 9.24 million needles and syringes were dispensed through the NSW Needle and Syringe Program.

\section{Preventing the spread of HIV}

Without needle and syringe programs (NSPs), HIV has the potential to spread rapidly among IDU populations, and from there to the rest of the population. The rapid spread of HIV among IDU in localities without NSP has been well documented. These reports show a striking similarity in the rapidity of both the spread and the resulting high prevalence of cases. In Mykolayev in the Ukraine, prevalence was estimated to have risen from two per cent in 1995 to 57 per cent in 1996. In Edinburgh, prevalence rose from one per cent to 40 per cent in one year and, in Bangkok, prevalence rose from two per cent to 40 per cent in two years. ${ }^{1}$

The strongest evidence for the efficacy of NSPs was obtained by an Australian analysis using a non-selective meta-analytic methodology based on more than 3000 articles in the research literature. ${ }^{2}$ From these, the authors identified 81 cities worldwide in which changes in the 


\section{FIGURE 3}

REPORTS OF SELECTED INFECTIOUS DISEASES, NSW, JANUARY 1994 TO OCTOBER 1998, BY MONTH OF ONSET

These are preliminary data: case counts in recent months may increase because of reporting delays

cases

cases

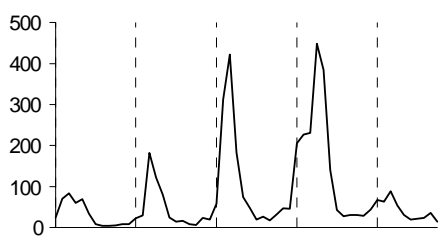

Arbovirus

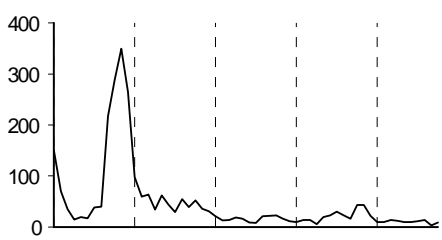

Measles

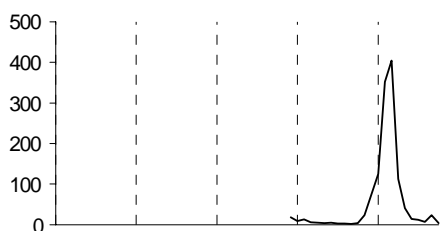

Cryptosporidiosis (not reportable before December 1996)

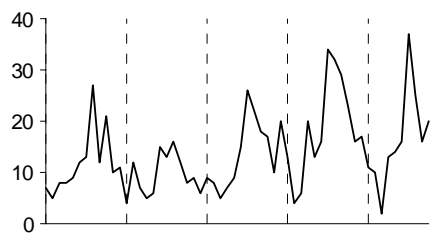

Meningococcal disease
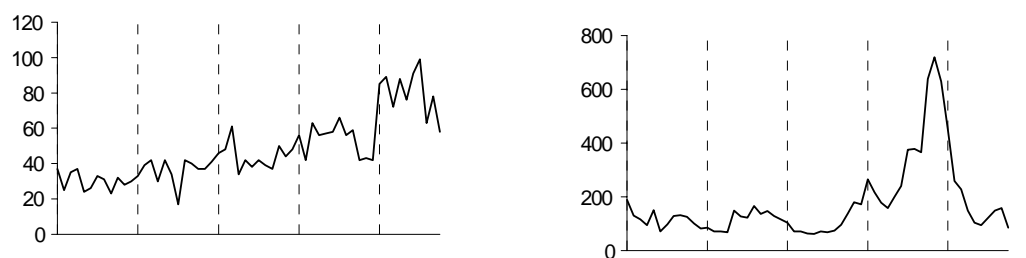

Gonorrhoea

Pertussis
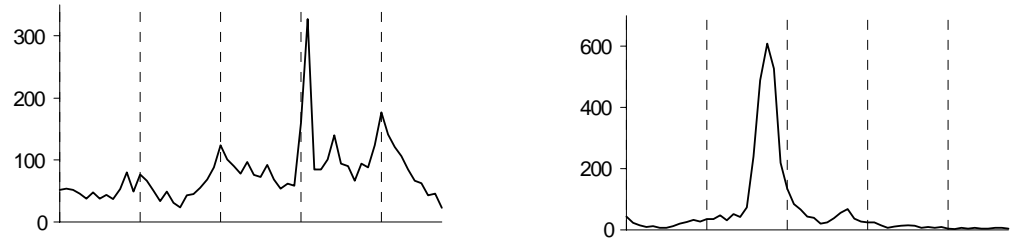

Hepatitis A

Rubella
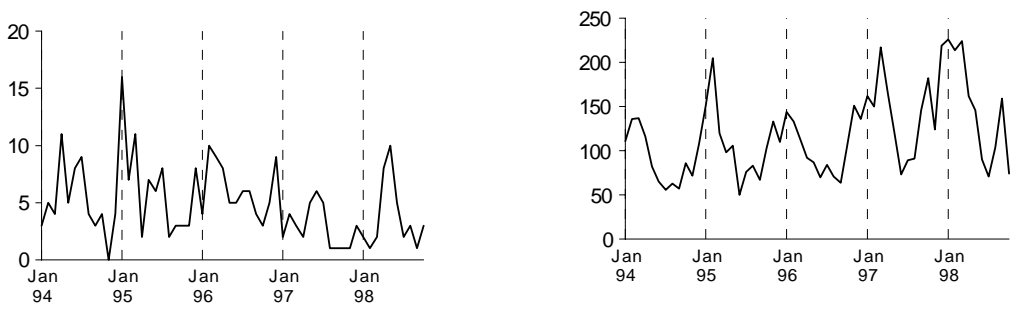

Legionellosis

Salmonellosis 
HIV antibody seroprevalence among IDUs had been assessed over time. NSPs were present in 29 and absent in 52 of these cities. The study found that HIV prevalence had decreased by 5.8 per cent per annum in the 29 cities with NSPs, and increased by 5.9 per cent per annum in the 52 cities without such programs.

\section{A model approach}

Lurie and Drucker noted that the effectiveness of Australian NSPs in minimising new HIV infections made them a desirable model for the development of policy in the United States. ${ }^{3}$ Recently, it has been estimated that approximately 36 per cent of newly diagnosed AIDS cases in the United States are IDU-related and that injecting drug use is the most frequently reported source of new HIV infections. ${ }^{4}$

The rapid increase in HIV transmission in an injecting population was documented recently in Vancouver, Canada, despite the presence of an NSP. ${ }^{5}$ Previously, the prevalence of HIV among IDUs was similar to Australia'sless than two per cent. However, this increased to around 23 per cent over 18 months. This was thought to be due to several factors, including:

- a high level of needle sharing

- unstable housing

- the use of public 'shooting galleries' with insufficient numbers of needles and syringes distributed to meet the new demand

- an increase in cocaine use with an associated higher frequency of injecting.

Research indicated that changes in environmental conditions and social circumstances created by housing and public health policy affect injecting behaviour and play an important role in determining the health of IDUs. Small changes in public health policy may be enough to produce both positive and sometimes unanticipated negative consequences for injecting drug users.

\section{Cost savings attributed to needle and syringe programs}

The public health benefits and cost saving generated by the NSW Needle and Syringe Program are significant. The independent evaluator of the National HIV/AIDS Strategy 1993-94 through 1995-96, Professor RGA Feachem, estimated in his report that, in 1991, Australian NSPs had prevented approximately 2900 cases of HIV infection. This represents a saving of $\$ 266$ million in avoided treatment costs. ${ }^{6}$

\section{Prevention of Hepatitis C}

The prevalence of hepatitis $\mathrm{C}(\mathrm{HCV})$ among Australian IDUs is much higher than that of HIV. This is due to a number of factors, given that HCV was already present among IDUs before the virus was identified and before prevention efforts (such as NSPs) could be put in place. In addition, $\mathrm{HCV}$ is much more readily transmitted than HIV. In Australia, it is currently estimated that about 80 per cent of HCV infections were acquired through injecting drug use, seven per cent through receipt of blood or blood products, and the remainder through other routes such as tattooing, body piercing and needlestick injury. ${ }^{7}$ However, evidence has now emerged which shows that HCV transmission rates among new injectors (injecting for less than three years) dropped from 34 per cent in 1996 to 13 per cent in $1997 .{ }^{8}$

\section{Possible reduction in overdose deaths}

Another public health benefit of providing NSPs is a likely reduced incidence of fatal overdose. Such a reduction is made possible through the provision of overdose prevention education for IDU-affected communities and family members and through the availability of cardiopulmonary resuscitation (CPR) and other interventions at injecting locations. At one inner-city location, NSP workers reported 180 serious overdoses in the six months to the end of October 1998. Due to the presence of NSP workers who administered CPR, no fatalities were reported on any of these occasions. NSP workers continue to provide education to IDUs regarding overdose prevention and appropriate responses in overdose situations.

\section{Promoting access to other prevention programs}

NSP staff are often the first point of contact for IDUs into the mainstream of health care. They are able to refer IDUs to a variety of relevant agencies, including drug and alcohol services, detoxification services, methadone treatment services, counselling services, and other drug treatment programs. Staff also continue to provide health and safety education to NSP clients including disease prevention, vein care, nutritional advice, and issues arising out of living with hepatitis $\mathrm{C}$ and HIV or AIDS.

\section{Reducing needle and syringe litter}

Where resources permit, NSP staff also participate in community education regarding the public health benefits of NSPs and community clean up of inappropriately discarded needles and syringes. They also provide ongoing education to IDUs of the need to exchange or dispose of used injecting equipment safely and responsibly.

In addition, NSW Health has introduced the Needle Clean Up Hotline (1800 633 353). Members of the public can now call a toll-free number from anywhere in NSW to discuss problems caused by needle and syringe littering. Inappropriately discarded needles and syringes will be removed upon request. 


\section{Conclusion}

IDUs are the most strategically important target population for HIV prevention. Epidemics among this group can be unpredictable, occur rapidly, and have the potential to greatly increase transmission rates in non-IDU women, children and other groups.

The weight of evidence demonstrates that NSPs are effective in reducing HIV infections among IDUs. Implementation of NSP strategies in NSW has been of high quality and effectiveness, and has contributed to maintaining low rates of HIV infection among IDUs. The public health benefit and economic value of NSPs is now being increasingly recognised.

\section{REFERENCES}

1. UNAIDS/WHO. Report on the global HIV/AIDS epidemic. www.unaids.org/unaids/ World Health Organisation, June 1998.

2. Hurley D, Jolley J, Kaldor J. Effectiveness of needleexchange programmes for prevention of HIV infection. Lancet 1997; 349: 1797-1800.

3. Lurie P, Drucker E. An opportunity lost: HIV infections associated with lack of a national needle-exchange programme in the USA. Lancet 1997; 349: 604-608.

4. Singer M, Himmelgreen D, Dushav R, et al. Variation in Drug Injecting Frequency Among Out-of-Treatment Drug Users in a National Sample, Am J Drug Alcohol Abuse, May 1998; 24(2); 321-341.

5. Strathdee A, Patrick D, and Currie S, et al. Needle exchange is not enough: Lessons from the Vancouver Injection Drug Use Study. AIDS 1997; 11(8): 59-65.

6. Feachem RGA. Valuing the past ... investing in the future, Evaluation of the National HIV/AIDS Strategy 1993-94 to 1995-96. Canberra: AGPS, November 1995; 91.

7. Parliament of NSW Legislative Council. Hepatitis $C$ : The Neglected Epidemic, Inquiry into Hepatitis C in NSW, Sydney: Standing Committee on Social Issues, Report No. 16; November 1998; 57.

8. National Centre in HIV Epidemiology and Clinical Research. Annual Surveillance Report 1998, HIV/AIDS and Related Diseases in Australia. Darlinghurst (Sydney): National Centre in HIV Epidemiology and Clinical Research, 1998; 71.

\section{PUBLIC HEALTH EDITORIAL STAFF}

The NSW Public Health Bulletin is a publication of the NSW Department of Health. The editor is Dr Lynne Madden, Manager, Public Health Training and Development Branch, NSW Health Department. Michael Giffin is production manager.

The Bulletin aims to provide its readers with population health data and information to motivate effective public health action.

\section{Submission of articles}

Articles, news and comments should be 1000 words or less in length and include a summary of the key points to be made in the first paragraph. References should be set out in the Vancouver style, described in the New England Journal of Medicine, 1997; 336: 309-315. Send submitted articles on paper and in electronic form, either on disc (Wordperfect or Word for Windows are preferred), or by email. The article must be accompanied by a letter signed by all authors. Full instructions for authors are available on request from the editor.

\section{Editorial correspondence}

Please address all correspondence and potential contributions to The Editor, NSW Public Health Bulletin, Locked Mail Bag 961, North Sydney NSW 2059 or to Lmadd@doh.health.nsw.gov.au. Tel (02) 9391 9956, Fax (02) 93919232.

\section{Distribution}

Please contact your local Public Health Unit or telephone (02) 93919942 to obtain copies of the NSW Public Health Bulletin or to notify us of a change of address. The Bulletin can be accessed via the Internet from http:// www.health.nsw.gov.au/public-health/phb/phb.html, the Department's Web site.

Back issues can be obtained from the Better Health Centre, Locked Mail Bag 961, North Sydney NSW 2059. 
TABLE 2

INFECTIOUS DISEASE NOTIFICATIONS RECEIVED IN OCTOBER 1998 BY AREA HEALTH SERVICES

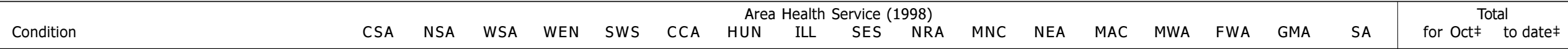
Blood-borne and sexually transmitted AIDS

HIV infection*

Hepatitis B: acute viral*

Hepatitis B: other*

Hepatitis C: acute viral

Hepatitis D: unspecified*

Hepatitis: acute viral (not otherwise specified)

Chlamydia (genital)

Gonorrhoea*

Vector-borne

Arboviral infection*

Zoonoses

Brucellosis*

Q fever*

Respiratory and other

Blood lead level

Legionnaires' disease

Leprosy

Meningococcal infection (invasive)

Mycobacterial tuberculosis

Mycobacteria other than T

Adverse event after immunisation

Haemophilus influenzae b infection (invasive)

Measles

Mumps*

Pertussis

Rubella*

Faecal-ora

Botulism

Cholera*

Cryptosporidiosis

Fod-borne illness (not otherwise specified)

Gastroenteritis (in an institution)

Haemolytic uraemic syndrome

Hepatitis A

Hepatitis E
Listeriosis*

Salmonellosis (not otherwise specified)*

Typhoid and paratyphoid*

Verotoxin-producing $E$. coll

$\begin{array}{llllllllllllllllll}7 & 2 & 3 & - & - & - & - & - & 4 & - & - & - & - & - & - & 1 & - \\ 1\end{array}$

$*$ lab-confirmed cases only $\quad$ \# includes cases with unknown postcode

CSA $=$ Central Sydney Area

NSA $=$ Northern Sydney Area

WEN $=$ Wentworth Area

SWS $=$ South Western Sydney Area

$\mathrm{CCA}=$ Central Coast Area

HUN = Hunter Area

$\mathrm{SES}=$ South Eastern Sydney Area

NRA $=$ Northern Rivers Area

MAC = Macquarie Area

MWA $=$ Mid Western Area

NEA = New England Area

FWA $=$ Far West Area 